\title{
12 Student Artists on Braille Babbles: A Catalogue
}

\section{Josie Ament}

"When a person does not have sight their hands become their way of seeing. The sense of touch becomes a bridge to knowledge and ideas about the world around them but also the way they encounter Braille. The circles in these collages are symbolic of Braille dots while also working to highlight other senses and ways of communicating. I aim to question how one comes to an understanding through the sense of touch, smell and hearing but also how much one can communicate through voice, touch or body language.

I am currently in my $4^{\text {th }}$ year in the Concurrent Education program at Brock University, majoring in fine arts. I work in multiple mediums including drawing, painting, collage, darkroom photography and installation. My work deals with themes of instability, memory and often questions identity. I am interested in the idea of truth and how it is in constant flux." (JA)

\section{Kristin Clancy}

"With the rise in social networking sites, we as a society have become obsessed with updating others about what is happening right at every moment. With Instagram, we spend so much time trying to take a perfectly composited photo and selecting the best filter, that we are editing our life updates to make them seem more ideal to others. Inspired by the photos of blind instagrammer Tommy Edision (@blindfilmcritic), I aimed to portray a more accurate view of what I was in fact experiencing throughout a day, by blindly taking photos and selecting filters." $(\mathrm{KC})$

\section{Holley Corfield}

The Language of Visual Symbols

"In The Language of Visual Symbols the imagery and the medium work together to play with the notion of communication. The abstract representation of smoke is juxtaposed with the formula present in the player piano rolls. An ideology of communication is presented in a traditional form, as both player piano rolls and smoke signals are old paradigms of communication. For example, smoke signals were once used for communication between soldiers who were stationed along the Great Wall of China, the smoke would be used to alert each other of impending enemy attacks. While the smoke signals date back to ancient times piano rolls date back to the 19th century. They are a series of long rolls of paper which have perforation in them. The perforated holes represent note control data, as the roll moves along the piano reads the notes to play music on the piano. Both piano rolls and smoke signals are lacking the traditional western language yet they are able to communicate meaning and search for a truth in the purity of reality." (HC) 


\section{Nick Cowan-Nagora}

Blurred dots, blurry vision and how it fills in space, investing darkness with pale trails of light. Language, barely readable or traceable, nevertheless expands to the limits of the image - and probably beyond. (CP)

\section{Vicky Gouvis}

\section{Lorna Dee Cervantes}

Lorna Dee Cervantes is a feminist chicana poet whose work evokes cultural differences (Native American, Mexican, Anglo, African-American) and addresses the question of bilingualism. (Cervantes was raised with English as sole language.) Vicky's Gouvis's piece illustrates Cervantes's "The Body as Braille" published in Emplumada (1981). (CP)

\section{Kevin Greene}

“I can't see where I'm going”

Bumper sticker

"How absurd would it be for a blind person to have this bumper sticker on their car? That sentence alone throws out many quandaries, one more so than others: blind people shouldn't have a car since they cannot see where they are going. Used to show your support, garner a laugh or display your ignorance, the bumper sticker tends to carry a great deal of baggage with it. My piece is meant to display the nonsensicality and ridiculousness of the bumper sticker." (KG)

\section{Jennifer Huang}

"Language is how we communicate, but it is not limited to speaking. I use photography as my visual language to attract the viewer with its imaginative, evocative, and dreamlike reflections. I have always been fascinated by the idea of reflection and the material of glass such as liqueur bottles, vases, perfume bottles and kaleidoscopes. This piece was created to visually communicate with the viewer, and more importantly to celebrate languages." ( $\mathrm{JH})$

\section{Sonya Kloostera}

Language has its mechanics, grammatical and stylistic. This piece materializes the wellorganized construction of communication as if it were a game to play with rather than a set of rules to learn by heart. The linguistic code is here an object looking like a spinning device; we are invited to let your hands follow the thread. (CP) 


\section{Ashlin LaPointe}

Language is evanescent just like music in a children's song or a piece of paper in a fire. However heard, seen or felt, it cannot be caught or imprisoned. Rather, it consumes itself like a light in the dark. (CP)

\section{Helen Slee}

"Thematic prompts: Braille, Babble, Multilingual, and Language. This piece is inspired by Mark Twain's 'Kindness is a Language that the blind can see and the deaf can hear', which I believe is articulating that actions speak louder than words and, while language and verbal/written communication binds us together, it also divides. There is a more easily understood and kinder form of communication in active human interaction.

In this piece I am trying to show that the many languages of earth can act as a barrier to kindness, and that simple acts which reach out to someone in need are more powerful, more beautiful, and more easily understood by all people, no matter their language or communication abilities. Actions speak louder than words.

Works Cited:

'Mark Twain Quotes'. ThinkExist.com Quotations. ThinkExist.com 1999-2013. Web. http://thinkexist.com/quotation/kindness_is_a_language_which_the_deaf_can_hear/164698.html Kindness. "Love is the Priority". Food, Faith, and Fellowship Blog. 27 August 2012. Web. http://foodfaithfellowship.blogspot.ca/2012_08_01_archive.html

'Kindness' Translated from Google Translator into 66 languages. http://translate.google.ca/ Afrikaans Czech Greek Korean Romanian Ukrainian Albanian Danish Gujarati Lao Russian Urdu Arabic Dutch Haitian Creole Latin Serbian Vietnamese Armenian English Hebrew Latvian Slovak Welsh Azerbaijani Esperanto Hindi Lithuanian Slovenian Yiddish Basque Estonian Hungarian Macedonian Spanish Belarusian Filipino Icelandic Malay Swahili Bengali Finnish Indonesian Maltese Swedish Bulgarian French Irish Norwegian Tamil Catalan Galician Italian Persian Telugu Chinese Georgian Japanese Polish Thai Croatian German Kannada Portuguese Turkish" (HS)

\section{Rebekah Steele But Now I See}

"But Now I See is a piece which speaks to spiritual blindness rather than physical blindness. The text is formed from the first two verses of the famous hymn Amazing Grace, and the image is composed of a porcelain figure of the baby Jesus, who is clean and bright amidst the wreckage of his surroundings. It relates to the artist's personal experience with discovering Christian faith, as well as the story behind the writing of Amazing Grace. The piece also highlights the transformations of language; the song lyrics were typed into a Braille-translator online, and the 
Braille was copied back into a Word document, resulting in jumbled combinations of text and symbols. The title is written in Greek, one of the original languages of the Bible, and the verses are written out in Braille. This inclusion of multiple languages explores the beauty of one message being understood by people of all different cultures and backgrounds." (RS)

\section{Shawndra White}

"I wanted to show how the Pedestrian Signal has developed over time to help the visually impaired and colourblind cross the street safely by using Found Images and part of a poem by Tom Sleigh. Karl Peglau from Germany created the red and green men in the hats in 1961. Up until this point the pedestrians had to use the same signals as the vehicles to cross the street which was hard for the visually impaired and colourblind to see. The art work shows not only how the little green and red men have developed in different countries including female cross walks in the Netherlands but also to the Accessible Pedestrian Signal (APS). APS is used to help guide the blind through sound safely across the street. Although APS has been around since the 1960 's in Europe, the APS has only begun to expand and perfect the system in the late 1990's in North America." (SW)

(CP) - Catherine Parayre 